\title{
Insights into Elution of Anion Exchange Cartridges: Opening the Path towards Aliphatic ${ }^{18}$ F-Radiolabeling of Base-Sensitive Tracers
}

\author{
Klas Bratteby, ${ }^{+, \#, \S}$ Vladimir Shalgunov, ${ }^{+, \S}$ Umberto Battisti, ${ }^{+}$Ida Nyman Petersen,,${ }^{\S}$ Sara Lopes van den Broek, ${ }^{\dagger}$ Tomas Ohlsson, ${ }^{\#}$ Nic \\ Gillings, ${ }^{\S}$ Maria Erlandsson, ${ }^{*}$ and Matthias M. Herth ${ }^{+, s, *}$ \\ ${ }^{+}$Department of Drug Design and Pharmacology, University of Copenhagen, Jagtvej 160, 2100 Copenhagen, Denmark \\ * Department of Radiation Physics, Skåne University Hospital, Barngatan 3, 22242 Lund, Sweden \\ ${ }^{\S}$ Department of Clinical Physiology Nuclear Medicine \& PET, Rigshospitalet, Blegdamsvej 9, 2100 Copenhagen, Denmark
}

KEYWORDS: Fluorine-18, aliphatic radiolabeling, anion-exchange, QMA, base sensitivity, elution conditions

\begin{abstract}
Aliphatic nucleophilic substitution $\left(\mathrm{S}_{\mathrm{N}} 2\right)$ with $\left[{ }^{18} \mathrm{~F}\right]$ fluoride is the most widely applied method to prepare ${ }^{18} \mathrm{~F}-\mathrm{labeled}$ positron emission tomography (PET) tracers. Strongly basic conditions commonly used during ${ }^{18} \mathrm{~F}$-labeling procedures inherently limit or prohibit labeling of base-sensitive scaffolds. The high basicity stems from the tradition to trap $\left[{ }^{18} \mathrm{~F}\right]$ fluoride on anion exchange cartridges and elute it afterwards with basic anions. This sequence is used to facilitate the transfer of $\left[{ }^{18} \mathrm{~F}\right]$ fluoride from an aqueous to an aprotic organic, polar reaction medium, which is beneficial for $\mathrm{S}_{\mathrm{N}} 2$ reactions. Furthermore, this sequence also removes cationic radioactive contaminations from cyclotronirradiated $\left[{ }^{18} \mathrm{O}\right]$ water from which $\left[{ }^{18} \mathrm{~F}\right]$ fluoride is produced. In this study, we developed an efficient elution procedure resulting in low basicity that permits $\mathrm{S}_{\mathrm{N}} 2{ }^{18} \mathrm{~F}$-labeling of base-sensitive scaffolds. Extensive screening of trapping and elution conditions (>1000 experiments) and studying their influence on the radiochemical yield (RCY) allowed us to identify a suitable procedure for this. Four PET tracers and three synthons could be radiolabeled in substantially higher RCYs (up to 2.5-fold), even from lower precursor amounts, using this procedure. Encouraged by these results, we applied our low basicity method to the radiolabeling of highly base-sensitive tetrazines, which cannot be labeled using stateof-art direct aliphatic ${ }^{18} \mathrm{~F}$-labeling procedures. Labeling succeeded in RCYs of up to $20 \%$. We believe that our findings facilitate PET tracer development by opening the path towards simple and direct $\mathrm{S}_{\mathrm{N}} 2{ }^{18} \mathrm{~F}$-fluorination of base-sensitive substrates.
\end{abstract}

Positron emission tomography (PET) is a powerful and versatile molecular imaging tool to diagnose disease or monitor treatment progress. ${ }^{1-3}$ The most widely used PET radionuclide is fluorine-18 $\left({ }^{18} \mathrm{~F}\right)$, as it can be produced in large amounts (>300 GBq) and possesses almost ideal nuclear decay characteristics for molecular imaging. ${ }^{4}$ Its low positron energy ensures high image resolution, while the half-life of approximately $110 \mathrm{~min}$ allows for production of ${ }^{18} \mathrm{~F}$-radiopharmaceuticals for a large number of patients and their distribution to remote sites several hundred kilometers away. ${ }^{2,5} \mathrm{Nu}-$ cleophilic aliphatic ${ }^{18} \mathrm{~F}$-fluorination $\left(\mathrm{S}_{\mathrm{N}} 2\right)$ is one of the most widely applied ${ }^{18} \mathrm{~F}$-radiolabeling methods. ${ }^{6,7}$ However, the standard approach (Figure 1 ) to purify and concentrate $\left[{ }^{18} \mathrm{~F}\right]$ fluoride requires strong bases. ${ }^{8-10}$ The resulting basic environment hinders (or even prevents) ${ }^{18} \mathrm{~F}$-fluorination of base-sensitive substrates while triggering side-reactions such as hydrolysis, elimination and/or decomposition of precursors/products. ${ }^{8,11-13}$ To address this challenge, a wide variety of methods to perform $\mathrm{S}_{\mathrm{N}} 2{ }^{18} \mathrm{~F}$-fluorinations under less basic conditions have been developed over the last decades. ${ }^{8,14-18}$ However, none of these methods appear to be ideal, as they only utilize a fraction of the available radioactivity, need special and non-standard precursors/equipment, or are difficult to implement. ${ }^{19-21}$ Recently, Mossine et al. have shown that replacement of strong basic anions with weak organic bases significantly increased the radiochemical yields ( $\mathrm{RCY}$ ) for $\mathrm{Cu}$-mediated aromatic ${ }^{18} \mathrm{~F}$-fluorinations. ${ }^{8}$ In light of this, we decided to explore the relationships between the $\left[{ }^{18} \mathrm{~F}\right] \mathrm{flu}$ oride elution efficiency for a given preconditioning/eluting anion combination and its possibility to activate $\left[{ }^{18} \mathrm{~F}\right]$ fluoride for $\mathrm{S}_{\mathrm{N}} 2$ reactions (Figure 1). We hypothesized that, by carefully mapping elution conditions and analyzing corresponding $\mathrm{S}_{\mathrm{N}} 2{ }^{18} \mathrm{~F}$-fluorination yields, we would be able to tailor the anion combination in such way to efficiently radiolabel base-sensitive substrates, which cannot currently be radiolabeled using standard reaction conditions.

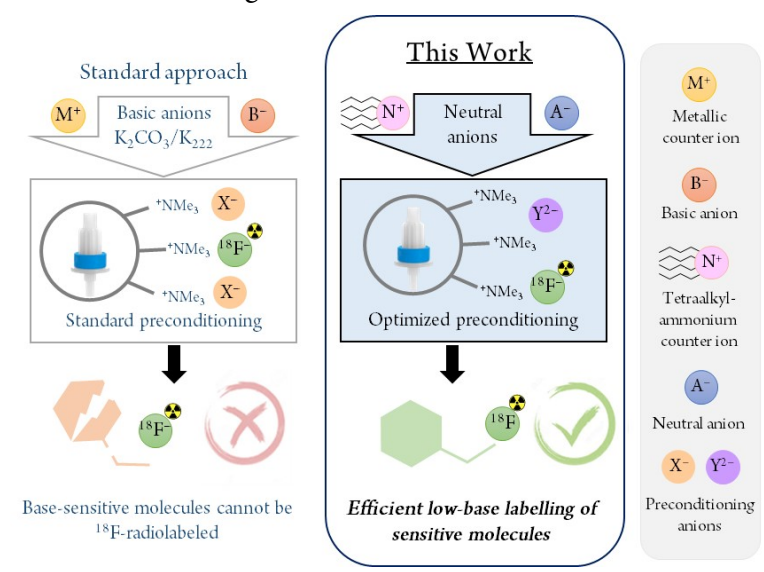

Figure 1. Optimization of $\left[{ }^{18} \mathrm{~F}\right]$ fluoride elution method. Standard approach (left) promotes side reactions and precludes the labeling of base-sensitive molecules, while careful choice of anions to exchange with $\left[{ }^{18} \mathrm{~F}\right]$ fluoride promotes labeling (right). 


\section{Results and discussion}

The radiochemical yield (RCY) of a labeling procedure is a measure of the proportion of decay corrected and isolated product - with respect to the starting radioactivity. Consequently, all steps of a labeling procedure contribute to the $\mathrm{RCY} .{ }^{22}$ We reasoned that the $\mathrm{RCY}$ of an $\mathrm{S}_{\mathrm{N}} 2{ }^{18} \mathrm{~F}$-fluorination is primarily determined by two factors: 1 ) The elution efficiency (EE) of the trapped $\left[{ }^{18} \mathrm{~F}\right]$ fluoride and 2) the reaction efficiency (radiochemical conversion, RCC) (Figure $2 A) .^{23,24}$ The latter can be optimized with respect to time, precursor amount, solvent and temperature as well as with respect to the basicity of the reaction medium and the solubility and activation of $\left[{ }^{18} \mathrm{~F}\right]$ fluoride. Whereas the first four parameters are frequently optimized $^{25}$, the last three are often neglected, even though they are crucial for the labeling of base-sensitive substrates, as they determine the base concentration of the reaction. The aforementioned parameters are strongly dependent on how the anion exchange cartridge (AEC) is preconditioned and eluted. ${ }^{12}$ In order to study the influence of preconditioning and elution conditions on the RCY, we decided to investigate the EE and the RCC independently. To approximate the expected efficiency of the whole labeling procedure (RCY), we defined a theoretical measure, which we named the pseudo radiochemical yield ( $\mathrm{pRCY}$ ). This measure was used to evaluate the applied labeling conditions.

$$
\mathrm{pRCY}=\mathrm{EE}^{*} \mathrm{RCC}
$$

Screening of elution conditions. Initially, we screened a broad set of different elution conditions (>500 experiments) with the aim to identify a sufficient $\mathrm{EE}$ that simultaneously resulted in a low basicity eluate. For simplicity, only the commonly used Sep-Pak Light QMA (130 mg resin loading) AEC was investigated. ${ }^{26}$ Furthermore, we explored how different preconditioning anions influence the $\mathrm{EE}$, as this could be a major contributing factor in subsequent fluorinations (Figure $2 A$ ). We decided to precondition cartridges with relatively non-basic $\mathrm{Cl}^{-}$and $\mathrm{HCO}_{3}{ }^{\circ}$ anions. As elution solvents, we studied water and two different $\mathrm{MeCN} / \mathrm{H}_{2} \mathrm{O}$ mixtures. These elution solvents were chosen to find the best compromise between the better EEs of a higher water content and the considerably shorter azeotropic distillation process associated with a lower water content.

In all experiments, cyclotron produced aqueous $\left[{ }^{18} \mathrm{~F}\right]$ fluoride was quantitatively trapped. The concentrations resulting in an $\mathrm{EE}$ of $90 \%$ were calculated by fitting the Hill equation to the data (Table 1$)$. We decided to use this value as we believe that the initial activity loss during the trapping and elution step should be minimized to $\leq 10 \%$. Various types and concentrations of eluting anions were screened to identify minimal concentrations. In addition to commonly applied eluting anions such as carbonates, bicarbonates or oxalates, we investigated organic bases such as DBU, $\mathrm{Et}_{3} \mathrm{~N}, \mathrm{DIPEA}$ and DMAP. These bases deprotonate water molecules, forming $\mathrm{OH}^{-}$anions in situ, which displace $\left[{ }^{18} \mathrm{~F}\right]$ fluoride from AECs. During the subsequent drying procedure, bases are removed through distillation, resulting in low basicity of the reaction mixture. We also investigated a range of neutral salts as eluting anions. In all cases, the EE showed a sigmoidal curve progression with a sharp decrease at a specific concentration depending on the preconditioning of the AECs and the eluting anions (Figure 2B). Bicarbonate preconditioned AECs generally required lower eluting anion concentrations compared to chloride preconditioned AECs. This effect is driven by the weaker interaction of chloride with the quaternary methyl groups of the resin compared to bicarbonates. ${ }^{8}$ As expected, the EE was higher for solvent mixtures containing more water. This improvement in EE was especially pronounced for organic bases, as higher water concentrations promoted in situ formation of $\mathrm{OH}^{-}$ions. The most efficient eluting anions were bivalent "standard reagent" anions $\left(\mathrm{K}_{2} \mathrm{CO}_{3} / \mathrm{K}_{222}\right.$ and $\mathrm{K}_{2} \mathrm{C}_{2} \mathrm{O}_{4} / 18 \mathrm{C} 6$ ) and "in situ formed $\mathrm{OH}^{-}$-anions" with organic bases (DBU and DIPEA) in higher water concentrations, whereas the neutral salts generally required higher concentrations of anions. For this reason, we decided to study the influence of eluting conditions on the RCC.

Trade-off between the EE and the RCC. In a previous study of elution conditions for aromatic ${ }^{18} \mathrm{~F}$-fluorodeboronations, the highest RCCs were achieved using the lowest concentrations of eluting anions. ${ }^{8}$ The best RCYs could be reached using a trade-off between the concentration of eluting anions that yielded in high RCCs and acceptable, but incomplete EE. The authors explained the observed trade-off with the base sensitivity of ${ }^{18} \mathrm{~F}$-fluorodeboronations. ${ }^{8,27,28}$ This observation inspired us to explore if such a trade-off between the EE and the RCC also exists for aliphatic ${ }^{18} \mathrm{~F}$-radiolabeling for base-sensitive compounds (Figure 2B). For this reason, we decided to study the influence of eluting conditions on the RCC and used them together with the EE to determine pRCYs. A model reaction was chosen for this purpose that was not particularly base sensitive, but allowed for fast and efficient screening (Figure 3A).

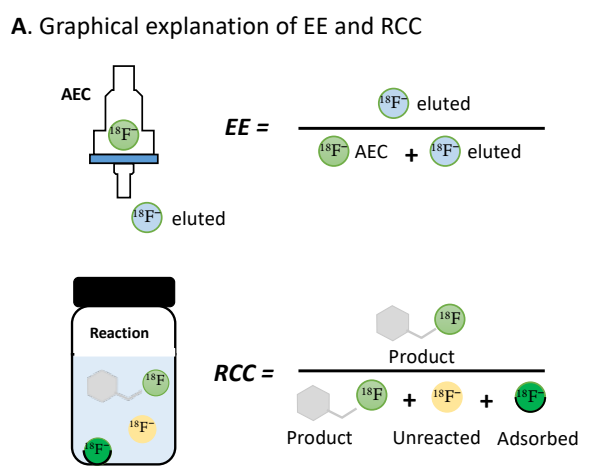

B. Hypothetical trade-off between EE and RCC for base-sensitive substrates

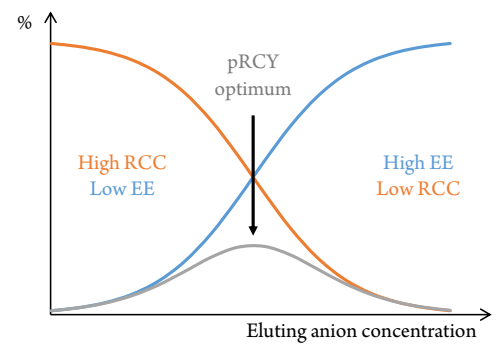

Figure 2. Hypothesized relationship between the elution efficiency (EE), the radiochemical conversion (RCC) and the pseudo radiochemical yield ( $\mathrm{pRCY}$ ) for base-sensitive compounds. (A) Definition of EE and RCC. RCCs were calculated including resolubilization of ${ }^{18} \mathrm{~F}$-fluoride, adsorbed to the glass vessel wall (see SI for further information). (B) Typical dependence of EE (sigmoidal curve, blue) and hypothetical dependence of RCC (brown) on the eluting anion concentration for base-sensitive compounds. Highest pRCY is a trade-off between the EE (as an indicator of the anion elution concentration) and the RCC, i.e. at an anion concentration resulting in sufficient elution with minimal influence on the basesensitive reaction. 
Table 1. Results from EE screening using different preconditioning- and eluting anions over a range of concentrations. The table displays concentrations of eluting anions in $\mathrm{mM}$ required to elute $90 \%$ of $\left[{ }^{18} \mathrm{~F}\right]$ fluoride from the QMA cartridge. These values were determined by fitting the Hill equation to a set of 7 elutions (5-100 mM of the eluting anion in $1 \mathrm{~mL}$ of eluting solvent $(5-100 \mu \mathrm{mol})$. Further details can be found in supporting information (Table S1). Colors indicate concentrations required to obtain EE 90\%, with white representing the lowest concentration and gradually darker blue for higher concentrations. $\mathrm{K} 222=\mathrm{Kryptofix}{ }^{\circledR} 222,18 \mathrm{C} 6=18-\mathrm{Crown}-6$

\begin{tabular}{|c|c|c|c|c|c|c|c|c|c|c|c|c|c|}
\hline \multicolumn{14}{|c|}{ Minimum concentration in $\mathrm{mM}$ required to elute $90 \%$ of the $\left[{ }^{18} \mathrm{~F}\right]$ fluoride from the respective anion exchange cartridge (ACE) } \\
\hline \multirow{2}{*}{$\begin{array}{l}\text { High conc. } \\
\text { Low conc. }\end{array}$} & \multirow{2}{*}{$\begin{array}{l}\ddot{\theta} \\
\ddot{\theta}\end{array}$} & \multicolumn{5}{|c|}{ "Standard reagents" } & \multicolumn{4}{|c|}{ "Organic bases" } & \multicolumn{3}{|c|}{ “Neutral salts" } \\
\hline & & $\begin{array}{l}\mathrm{K}_{2} \mathrm{CO}_{3} \\
/ \mathrm{K}_{222}\end{array}$ & $\begin{array}{l}\mathrm{KHCO}_{3}^{-} \\
/ \mathrm{K}_{222}\end{array}$ & $\begin{array}{l}\mathrm{KHCO}_{3}^{-} \\
/ 18 \mathrm{C} 6\end{array}$ & $\begin{array}{r}\mathrm{HCO}_{3}^{-} \\
\mathrm{Et}_{4} \mathrm{~N}^{+}\end{array}$ & $\begin{array}{l}\mathrm{K}_{2} \mathrm{C}_{2} \mathrm{O}_{4} \\
/ 18 \mathrm{C} 6\end{array}$ & $\mathrm{DBU}$ & $\mathrm{Et}_{3} \mathrm{~N}$ & DIPEA & DMAP & $\begin{array}{c}\mathrm{SO}_{4}{ }^{2-} \\
\left(\mathrm{Bu}_{4} \mathrm{~N}\right)_{2}{ }^{2+}\end{array}$ & $\begin{array}{c}\mathrm{OMs}^{-} \\
\mathrm{Bu}_{4} \mathrm{~N}^{+}\end{array}$ & KOTf \\
\hline \multirow{2}{*}{$\begin{array}{l}\text { QMA } \\
-\mathrm{Cl}^{-}\end{array}$} & $\mathrm{H}_{2} \mathrm{O}$ & 15 & 15 & 17 & 22 & 9.7 & 18 & $>200$ & 11 & $>200$ & 76 & 30 & 23 \\
\hline & $\begin{array}{c}\mathrm{MeCN} / \mathrm{H}_{2} \mathrm{O} \\
(90: 10)\end{array}$ & 48 & 90 & 116 & $>200$ & 82 & $>200$ & $>200$ & $>200$ & $>200$ & 138 & $>200$ & $>200$ \\
\hline \multirow{3}{*}{$\begin{array}{c}\text { QMA } \\
-\mathrm{HCO}_{3}^{-}\end{array}$} & $\mathrm{H}_{2} \mathrm{O}$ & 12 & 5.6 & 13 & 16 & 7.3 & 7.3 & 18 & 9.6 & 15 & 20 & 17 & 21 \\
\hline & $\begin{array}{c}\mathrm{MeCN} / \mathrm{H}_{2} \mathrm{O} \\
(50: 50)\end{array}$ & 8.2 & 13 & 14 & 21 & 7.7 & 6.3 & 31 & 12 & $>200$ & 41 & 25 & 31 \\
\hline & $\begin{array}{c}\mathrm{MeCN} / \mathrm{H}_{2} \mathrm{O} \\
(90: 10)\end{array}$ & 15 & 15 & 17 & 22 & 9.7 & 18 & $>200$ & 11 & $>200$ & 76 & 30 & 23 \\
\hline
\end{tabular}

We hypothesized that the lowest acceptable base concentration that resulted in reasonable pRCYs of this reaction would allow us to decide on which conditions to test with base-sensitive reactions. A pRCY of $10 \%$ was defined as the lowest acceptable limit. This limit was set since it would theoretically allow isolation of $375 \mathrm{MBq}$ final product from $5 \mathrm{GBq}$ of starting activity with a $45 \mathrm{~min}$ synthesis time taken into account. This starting amount is accessible even at radiopharmaceutical centers without direct access to a cyclotron and that are dependent on ${ }^{18} \mathrm{~F}$-deliveries. The radioactivity amount used for a single human PET scan is approximately $300 \mathrm{MBq}^{29}$ and as such, 375 $\mathrm{MBq}$ of labeled tracer is sufficient as a lower limit for this purpose. To reduce the number of experiments, we decided to determine the pRCY on elution conditions that result in an EE of 20, 50, 90 and $\sim 100 \%$. From our initial elution experiments (Table 1), we further decided to test only elutions based on a 50:50 MeCN/ $\mathrm{H}_{2} \mathrm{O}$ mixture. This decision is a compromise between the diminishing EE observed with a 90:10 mixture and the prolonged drying procedure ( $\sim 30 \mathrm{~min}$ compared to 10-15 min) when pure water was used.

Initial radiolabeling screen using a model reaction. In order to determine the trade-off between the EE and the RCC, 23 reactions were carried out to determine the minimal anion (base) concentration needed to obtain a pRCY of $>10 \%$ for our model compound (Figure 3A, Supporting information Table S2). Details of the workflow for the reactions and analyses can be found in the supporting information, Figure $S 2$. The anion concentration was varied, one eluting reagent from each category chosen - namely $\mathrm{K}_{2} \mathrm{CO}_{3} / \mathrm{K}_{222}$ for standard reagents, $\mathrm{Et}_{3} \mathrm{~N}$ for organic bases and $\mathrm{Bu}_{4} \mathrm{NOMs}$ for neutral salts - and two preconditioning anions $\left(\mathrm{HCO}_{3}{ }^{-}\right.$or $\left.\mathrm{Cl}^{-}\right)$were tested for each combination. The results are summarized in Figure 3B. No trade-off between the EE (as an indicator of the anion elution concentration) and the RCC could be identified for any of the reactions. For QMAs preconditioned with $\mathrm{HCO}_{3}^{-}$and eluted with $\mathrm{K}_{2} \mathrm{CO}_{3} / \mathrm{K}_{222}$, a linear dependency between the $\mathrm{EE}$ and the RCC was observed. Lower eluting anion concentration, and subsequent lower EE, was accompanied by lower RCC. This can be explained by the increased capability of the vessel's glass wall to adsorb $\left[{ }^{18} \mathrm{~F}\right]$ fluoride when the (bi)carbonate concentration in the eluate decreases. Adsorbed $\left[{ }^{18} \mathrm{~F}\right]$ fluoride is not accessible for labeling reactions and consequently, the RCC drops. A pRCY of $>10 \%$ could be achieved using $>3 \mathrm{mM} \mathrm{K} \mathrm{CO}_{3} / \mathrm{K}_{222}$ (interpolated from the elution curves, Figure $3 B)$. As such, we suggest that this should be the minimal elution concentration as a starting-point to explore if base sensitive structures can be labeled using $\mathrm{HCO}_{3}$ preconditioned QMAs and the according $\mathrm{K}_{2} \mathrm{CO}_{3} / \mathrm{K}_{222}$ elution mixture. Lower $\mathrm{K}_{2} \mathrm{CO}_{3} / \mathrm{K}_{222}$ concentrations would not be expected to result in acceptable RCYs for base sensitive substrates. Consequently, ${ }^{18} \mathrm{~F}$-labeling attempts would be futile if they cannot withstand $3 \mathrm{mM}$ of $\mathrm{HCO}_{3}$. QMA cartridges preconditioned with $\mathrm{Cl}^{-}$and eluted with $\mathrm{K}_{2} \mathrm{CO}_{3} / \mathrm{K}_{22}$ showed a similar trend. However, the RCC was further reduced in an exponential fashion with lower EE. This decrease stems from the capacity of the cationic QMA resin to adsorb (bi)carbonate ions. At lower concentrations, no or very little amounts of (bi)carbonate ions can pass through the QMA and are as such not available in the eluate to promote the ${ }^{18} \mathrm{~F}$ fluorination.

In contrast, $\mathrm{Cl}^{-}$ions from the $\mathrm{Cl}^{-}$preconditioned $\mathrm{QMA}$ are released from the resin during the elution process leading to competing chlorination and thus reducing the RCC further (Figure $3 \mathrm{~B}$ and supporting information Figure S3). Elutions using $\mathrm{Et}_{3} \mathrm{~N}$ or other organic bases such as DBU or DIPEA resulted in loss of ${ }^{18} \mathrm{~F}$-activity (5-50\%) during azeotropic distillation of the eluate and no ${ }^{18} \mathrm{~F}$-incorporation of the remaining activity into the precursor was observed (Figure 3B, Supporting information Table S2). This indicates that the organic

A. Model reaction used to optimize RCC

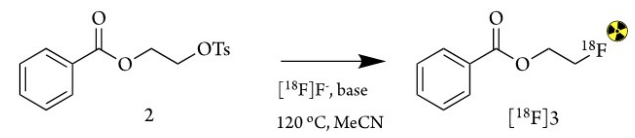

B. Results from initial radiolabelling experiments

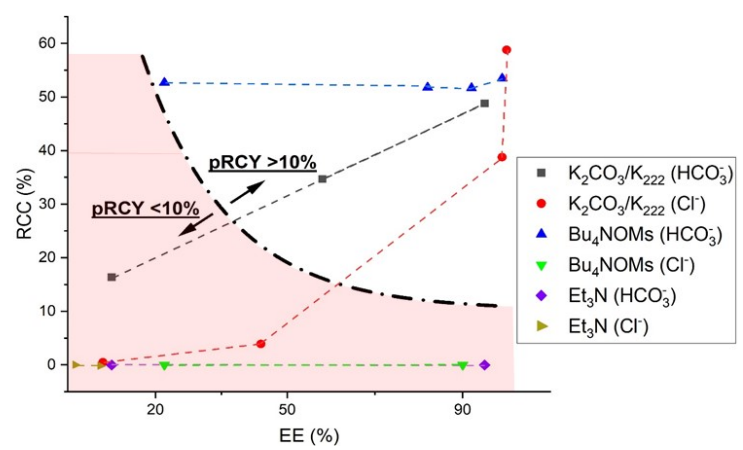

Figure 3: Model radiolabeling reaction using precursor 2 to form $\left[{ }^{18} \mathrm{~F}\right] 3$. (A) Reaction scheme. (B) Results from initial screening of different elution conditions at $120^{\circ} \mathrm{C}, 5 \mathrm{~min}$ in $\mathrm{MeCN}$. Concentration range 2-200 $\mu \mathrm{mol}$ of eluting anion depending on elution efficiency with preconditioning anions in brackets. Higher EE correlates to a higher eluting anion concentration. Detailed information in supporting information Table $S 2$. 
Bases do not generate conditions that are basic enough to promote $\mathrm{S}_{\mathrm{N}} 2$ fluorinations.Surprisingly, elution of the $\mathrm{HCO}_{3}$ preconditioned QMA using $\mathrm{Bu}_{4} \mathrm{NOMs}$ resulted in stable RCCs of around $50 \%$ independent of the elution anion concentration. pRCY $>10 \%$ could be reached for all tested conditions. Since ${ }^{18} \mathrm{~F}$-fluorination requires base and the OMs eluting anion is non-basic, the basicity must stem from the $\mathrm{HCO}_{3}$ preconditioning anion that co-elutes with the $\left[{ }^{18} \mathrm{~F}\right]$ fluoride when eluting the QMA with $\mathrm{Bu}_{4} \mathrm{NOMs}$.. No product was formed using the same conditions but preconditioning with the nonbasic anions: $\mathrm{OMs}^{-}$and $\mathrm{SO}_{4}{ }^{2-}$ (Supporting information Table S3). A previous study reported an ${ }^{18} \mathrm{~F}$-labeling strategy using neutral elution and preconditioning conditions and then subsequently basifying the eluted mixture with either $\mathrm{KHCO}_{3}, \mathrm{KOH}$ or $\mathrm{K}_{2} \mathrm{CO}_{3}$ before ${ }^{18} \mathrm{~F}$-fluorination. ${ }^{30}$ Unfortunately, in our hands, this strategy resulted in diminishing pRCYs for $\left[{ }^{18} \mathrm{~F}\right] 3$ with lower concentrations of base - in line with our previous results using potassium (bi)carbonates. This was due to the fact that up to $50 \%$ of ${ }^{18} \mathrm{~F}$-fluoride was adsorbed to the glass wall, despite using a protic solvent and high concentrations of $\mathrm{K}_{222}$. Rigorous stirring during the reaction to promote higher resolubilization of the adsorbed $\left[{ }^{18} \mathrm{~F}\right]$ fluoride did not improve the RCC (Supporting information Table S4). This prompted us to investigate further how preconditioning of the QMA cartridge combined with neutral elution could promote high $\mathrm{pRCYs}$ for low-base conditions.

Investigating the role of the preconditioning anion. Our data suggest that it is possible to utilize the basicity of the QMA cartridge preconditioning anion to promote ${ }^{18} \mathrm{~F}$-fluorinations when using non-basic salts for an efficient elution process. This combination could be used to minimize the base concentration in the reaction and protect base-sensitive precursors/tracers against degradation or to reduce base-promoted site-reactions. Therefore, we decided to test a number of preconditioning anions in combination with $\mathrm{Bu}_{4} \mathrm{NOMs}$ elution to determine their influence on the EE, RCC and ultimately, the pRCY ( Table 2). Interestingly, the EE was mainly dependent on the valency of the preconditioning anion rather than the $\mathrm{pK}_{\mathrm{a}}$, with a higher valency increasing the EE (Table 2 and Supporting information Table S5). Nucleophilic preconditioning anions such as $\mathrm{C}_{2} \mathrm{O}_{4}{ }^{2-}, \mathrm{AcO}^{-}$or $\mathrm{Cl}^{-}$should be avoided as they lower the RCC by outcompeting the $\left[{ }^{18} \mathrm{~F}\right]$ fluoride nucleophile, as confirmed by LC-MS analysis (supporting information Figure $S 3$ and $S 5$ ). As for any ${ }^{18} \mathrm{~F}$ fluorination, a certain basicity of the preconditioning anion is needed to promote the reaction. In our set-up, the reaction could proceed if preconditioning anions with a $\mathrm{pK}_{\mathrm{a}}$ of around 4 were used. For univalent preconditioning anions, a higher $\mathrm{pK}_{\mathrm{a}}$ resulted in a higher EE - in line with what has previously been reported. ${ }^{8}$ This observation follows the electroselectivity theory which is based on the Donnan potential. ${ }^{31}$ It allows to determine the electroselectivity of anions in heterogeneous systems, i.e. the selectivity coefficient between ions in solution and bound to the resin. For anions of the same valency at low concentrations, the dominating factor for the affinity to the resin is the Debye-Hückel activity coefficient which in turn is proportional to the $\mathrm{pK}_{\mathrm{a}}$, i.e. compounds with higher $\mathrm{pK}_{\mathrm{a}}$ values bind stronger to the resin. ${ }^{32}$ As such, preconditioning anions with a higher $\mathrm{pK}_{\mathrm{a}}$ than the fluoride ion facilitate elution of $\left[{ }^{18} \mathrm{~F}\right]$ fluoride from the QMA cartridge, since eluting anions can more easily displace fluoride from the resin compared to the more strongly bound preconditioning anions.

Quantifying the breakthrough of precondition anions. Given that the amount of base in the reaction mixture is determined by the $\mathrm{EE}$ of the preconditioning anion when non-basic elution ap-
Table 2. Radiolabeling of precursor 2 in $\mathrm{MeCN}$ at $120^{\circ} \mathrm{C}, 5$ min reaction time with $\mathrm{Bu}_{4} \mathrm{NOMs}$ elution $\left(20 \mathrm{mM}\right.$ in $\left.50 \% \mathrm{MeCN} / \mathrm{H}_{2} \mathrm{O}, 1 \mathrm{~mL}\right)$ using different preconditioning of the QMA.

\begin{tabular}{|c|c|c|c|c|}
\hline \multicolumn{5}{|c|}{ Screening of different preconditioning anions for elution by $\mathrm{Bu}_{4} \mathrm{NOMs}$} \\
\hline $\begin{array}{l}\text { Precon- } \\
\text { ditioning } \\
\text { anion }\end{array}$ & $\mathrm{pKa}^{54}$ & $\mathrm{EE}(\%)$ & $\operatorname{RCC}(\%)$ & $\mathrm{pRCY}(\%)$ \\
\hline $\mathrm{Cl}^{-}$ & -7.0 & 24 & 0 & 0 \\
\hline $\mathrm{OMs}^{-}$ & -1.9 & 28 & 0 & 0 \\
\hline $\mathrm{SO}_{4}^{2-}$ & $2.0(-9.0)^{\mathrm{a}}$ & 96 & 0 & 0 \\
\hline $\mathrm{H}_{2} \mathrm{PO}_{4}^{-}$ & 2.1 & $86^{\mathrm{b}}$ & 0 & 0 \\
\hline $\mathrm{C}_{2} \mathrm{O}_{4}{ }^{2-}$ & $4.2(1.3)^{\mathrm{a}}$ & 99 & $>5 \%$ & $>5 \%$ \\
\hline $\mathrm{AcO}^{-}$ & 4.7 & 45 & Traces & Traces \\
\hline $\mathrm{HCO}_{3}^{-}$ & 6.4 & $91.0 \pm 5.4^{\mathrm{c}}$ & $56.7 \pm 8.9^{c}$ & $52.1 \pm 6.9^{c}$ \\
\hline $\mathrm{HPO}_{4}{ }^{2-}$ & 7.2 & $95.6 \pm 0.9^{c}$ & $53.4 \pm 4.3^{\mathrm{c}}$ & $51.0 \pm 5.4^{\mathrm{c}}$ \\
\hline $\mathrm{CO}_{3}^{2-}$ & 10.3 & $92.0 \pm 6.3^{c}$ & $55.1 \pm 1.1^{c}$ & $50.7 \pm 4.3^{c}$ \\
\hline $\mathrm{PO}_{4}{ }^{3-}$ & 12.7 & $97.0 \pm 0^{c}$ & $74.3 \pm 14.2^{c}$ & $72.0 \pm 11.3^{\mathrm{c}}$ \\
\hline
\end{tabular}

${ }^{\mathrm{a}} \mathrm{pKa}$ for second protonation if only one of the divalent anion was investigated. ${ }^{b}$ Higher elution could be due to a mixture of mono- and divalent anions formed in aqueous solution. ${ }^{\mathrm{c}}$ Reactions performed in triplicates.

proaches are used, a precise quantification of the amount of preconditioning anion that is eluted into the reaction vessel would allow us to understand more thoroughly how these anions affect ${ }^{18} \mathrm{~F}$-fluorinations, especially for base-sensitive structures. In order to quantify the breakthrough of the preconditioning anions from the QMA cartridge, we estimated their concentration in the eluate (i) by $\mathrm{pH}$ measurements (Supporting information Table S6) and (ii) by quantitative NMR (qNMR) (Supporting information Table S7). In general, qNMR measurements provided higher precision than $\mathrm{pH}$ measurements, but could only be applied to the monovalent anions, $\mathrm{HCO}_{3}^{-}, \mathrm{H}_{2} \mathrm{PO}_{4}^{-}$and $\mathrm{OMs}^{-}$. Respective quantifications showed that the monovalent $\mathrm{HCO}_{3}$ preconditioning anion was proportionally displaced by $\mathrm{OMs}$, whereas the di- and trivalent $\mathrm{CO}_{3}{ }^{2-}$ and $\mathrm{PO}_{4}{ }^{3-}$ showed only minor displacement, even with high concentrations of OMs. This observation can be explained by the Donnan potential. Due to their multiple charge, multivalent anions interact with the cationic groups on the anion-exchange resin more strongly than monovalent anions. This effect is stronger than the one promoted by the $\mathrm{pK}_{\mathrm{a}}$-dependent Debye-Hückel activity effect. ${ }^{31}$ Therefore, perhaps counterintuitively, when the QMA cartridge is preconditioned with more basic multiple-charge anions (e.g. $\mathrm{PO}_{4}{ }^{3-}$ ), the basicity of the final elution mixture is lower than when a less basic anion with a lower charge (e.g. $\mathrm{HCO}_{3}{ }^{-}$) is used for QMA preconditioning. This is because the breakthrough of the multiple-charge anion is considerably lower. Finally, qNMR results also showed that the more acidic $\mathrm{H}_{2} \mathrm{PO}_{4}$ anion $\left(\mathrm{pK}_{\mathrm{a}}: 2.14\right.$ in $\mathrm{H}_{2} \mathrm{O}$ ) remained in its di-protonated form after it was eluted from the QMA. As such, it is able to reduce the basicity of the reaction mixture. However, the mixture remains basic enough to promote the ${ }^{18} \mathrm{~F}$-labeling step.

Improved resolubilization of $\left[{ }^{18} \mathrm{~F}\right]$ fluoride using $\mathrm{Bu}_{4} \mathrm{NOMs}$ as eluting anions. Adsorption of $\left[{ }^{18} \mathrm{~F}\right]$ fluoride on the wall of glass reaction vessels is a commonly observed phenomenon reducing RCCs under low basicity conditions. In comparison to standard systems using cryptands such as $\left[{ }^{18} \mathrm{~F}\right] \mathrm{KF} / \mathrm{K}_{222}$, tetraalkylammonium $\left[{ }^{18} \mathrm{~F}\right]$ fluoride is more lipophilic $\left(\mathrm{cLogD}_{7.4} \mathrm{cal}-\right.$ culated with Chemicalize software for $\mathrm{Bu}_{4} \mathrm{NF}$ is 1.32 and for the $\left.\mathrm{KF} / \mathrm{K}_{222}-0.41\right)$. Consequently, the solubility of such salts is higher in 
organic, polar aprotic solvents which are commonly used for fluorinations. For example, the use $\mathrm{Bu}_{4} \mathrm{NOMs}$ resulted in $10 \%$ less glass absorption as compared to using the corresponding $\mathrm{K}^{+} / \mathrm{K}_{222}$-mixture (Supporting information Table $S 8$ and $S 9$ ). As a result, $\left[{ }^{18} \mathrm{~F}\right]$ fluoride adsorption to glass walls is minimized and the amount available in the reaction solution increased. To further explore the potential of tetraalkylammonium salts in respect to reaction basicity and to in-

crease the resolubilization process of $\left[{ }^{18} \mathrm{~F}\right]$ fluoride, three additional salts with different physicochemical properties were studied. Table $3 a$ displays the rationale behind the selection of the respective salts. We decided to study the influence of these tetraalkylammonium salts, in combination with the most promising preconditioning anions (carbonate, bicarbonate, phosphate and hydrogen phosphate) that we identified in the preconditioning screening and three solvents (DMSO, $\mathrm{MeCN}$ and $t \mathrm{BuOH}$ ) which are commonly used solvents for aliphatic ${ }^{18} \mathrm{~F}$-fluorinations. ${ }^{25}$ The selection of solvents was based on their different ability to act as hydrogen bond donors (HBD) and/or hydrogen bond acceptors (HBA) (Table 3B). These factors can affect the solubility of the anions, thus influence the basicity and thus RCYs when labeling base-sensitive structures. ${ }^{33}$

Multiparametric radiolabeling screen using selected preconditioning anions and elution reagents. All possible combinations of preconditioning anions, eluting reagents and reaction solvent were tested (Figure 3A, Table 4). The non-basic eluting anions $\mathrm{OMs}^{-}$and OTf resulted in the highest $\mathrm{pRCY}$ in combination with multi-charged preconditioning anions, especially phosphates. These conditions led to very low preconditioning anion break-through and consequently lower base concentration in the eluate. This resulted in surprisingly high pRCYs while retaining high amounts of intact precursor (2) (Figure S14-15). $\mathrm{H}_{2} \mathrm{PO}_{4}$, as an acidic eluting anion, only resulted in good pRCYs when applied with carbonate or bicarbonate preconditioning anions. As indicated by the qNMR experiments, $\mathrm{H}_{2} \mathrm{PO}_{4}{ }^{-}$can lower the basicity of the carbonates and act as a buffer. Consequently, increasing the concentration of $\mathrm{H}_{2} \mathrm{PO}_{4}$ from $20 \mathrm{mM}$ to $\geq 50 \mathrm{mM}$ diminished the $\mathrm{pRCY}$ with the (bi)carbonate preconditioning anions as the eluate became too acidic to promote ${ }^{18} \mathrm{~F}$-labeling. This could explain the inconsistent $\mathrm{pRCYs}$ of the same elution of the phosphate preconditioned QMAs considering the possible variations in elution of the basic preconditioning anion $\left(\mathrm{PO}_{4}{ }^{3-}\right)$ at this concentration range. The balance of acidic elution and
Table 3. (A) Rationale behind the choice of tetraalkylated eluting anions. B) Physiochemical properties of the different solvent used for the multiparametric screen of elution conditions.

\begin{tabular}{|c|c|c|c|c|}
\hline A. & \multicolumn{2}{|c|}{$\begin{array}{l}\text { Tetraalkylammo- } \\
\text { nium salts }\end{array}$} & \multicolumn{2}{|l|}{ Rationale } \\
\hline & $\mathrm{Bu}_{4} \mathrm{NOTf}$ & & \multicolumn{2}{|c|}{$\begin{array}{l}\text { The lower pKa of OTf compared to the OMs of } \\
\mathrm{Bu}_{4} \mathrm{NOMs} \text { should displace lower amounts of pre- } \\
\text { conditioning anions during the elution process, re- } \\
\text { sult in a less basic eluate and enable therefore label- } \\
\text { ing tracers under milder reaction conditions. }\end{array}$} \\
\hline & $\mathrm{Bu}_{4} \mathrm{NH}_{2} \mathrm{PO}$ & & \multicolumn{2}{|c|}{$\begin{array}{l}\text { Due to the buffering capabilities of } \mathrm{Bu}_{4} \mathrm{NH}_{2} \mathrm{PO}_{4} \text {, } \\
\text { we decided to test this compound. This salt should } \\
\text { neutralize more basic preconditioning anions. }\end{array}$} \\
\hline & $\mathrm{Et}_{4} \mathrm{NHCO}_{3}$ & & \multicolumn{2}{|c|}{$\begin{array}{l}\text { Commonly used for elution in nucleophilic }{ }^{18} \text { F-ra- } \\
\text { diolabeling, used as a comparison. }{ }^{34,35}\end{array}$} \\
\hline \multirow[t]{4}{*}{ B. } & Solvent & & Proton affinity & H-bonding properties \\
\hline & DMSO & Aprotic & Protophilic & No HBD and HBA exist \\
\hline & $\mathrm{MeCN}$ & Aprotic & Protophobic & $\begin{array}{l}\text { No HBD and very weak } \\
\text { HBA }\end{array}$ \\
\hline & $t \mathrm{BuOH}^{\mathrm{a}}$ & Protic & Amphiprotic & $\begin{array}{l}\text { Both HBD and HBA } \\
\text { properties }\end{array}$ \\
\hline
\end{tabular}

basic preconditioning is regulated for the carbonates by $\mathrm{H}_{2} \mathrm{CO}_{3}$ formation escaping as $\mathrm{CO}_{2}$. However, for phosphate preconditioning all acidity from the elution remains in the eluate. This could pro-bably be optimized with lower concentrations of $\mathrm{Bu}_{4} \mathrm{H}_{2} \mathrm{PO}_{4}$ but then at the expense of a lower EE. Finally, the more frequently used elution reagent $\mathrm{Et}_{4} \mathrm{NHCO}_{3}$ resulted -as expected for base-insensitive precursors/tracers - in good pRCY for all preconditioning anions, comparable with the aforementioned high yielding elution conditions. Previous studies have reported efficient ${ }^{18} \mathrm{~F}$-fluorinations using $\mathrm{tBuOH} .{ }^{12}$ Surprisingly, the use of $\mathrm{tBOH} / \mathrm{MeCN}$ in this case only resulted in relatively low $\mathrm{RCC}$ for all tested elution conditions. However, the amount of intact precursor at the end of the reaction was significantly higher compared to reactions using $\mathrm{MeCN}$ or DMSO and otherwise identical conditions (Supporting information, Figure $S 15)$. This indicates that use of $t \mathrm{BuOH}$ in the solvent could be beneficial for very base-sensitive substrates, since the resulting mild labeling conditions lead to less degradation of the precursor/tracer, but at the expense of less efficient ${ }^{18} \mathrm{~F}$-incorporation.

Table 4. Pseudo radiochemical yields (pRCY) of the model compound $\left(\left[{ }^{18} \mathrm{~F}\right]\right.$ 3. Figure $\left.3 A\right)$ using different Tetraalkylammonium-salts in combination with various preconditioning anions in either $\mathrm{MeCN}$, DMSO or $t \mathrm{BuOH} / \mathrm{MeCN}(5: 1)$. Values gives as mean values with standard deviation, $\mathrm{n}=3$. Italic numbers and letters will be used to indicate combinations of elution and preconditioning, for example $1 \mathrm{~A}$ representing $\mathrm{HCO}_{3}$ - preconditioning with $\mathrm{Bu}_{4} \mathrm{NOMs}^{-}$elution.

\begin{tabular}{|c|c|c|c|c|c|c|}
\hline \multicolumn{7}{|c|}{ Testing combinations of preconditioning and eluting anions in various solvents } \\
\hline Preconditioning & Solvent & $\mathrm{Bu}_{4} \mathrm{NOMs}(A)$ & $\mathrm{Bu}_{4} \operatorname{NOTf}(B)$ & $\mathrm{Bu}_{4} \mathrm{NH}_{2} \mathrm{PO}_{4}(C)$ & $\mathrm{Et}_{4} \mathrm{NHCO}_{3}(D)$ & \\
\hline \multirow{3}{*}{$\mathrm{HCO}_{3}^{-}(1)$} & $\mathrm{MeCN}$ & $52.1 \pm 8.4 \%$ & $1.9 \%$ & $73.6 \pm 9.9 \%$ & $74 \pm 6 \%$ & \multirow{12}{*}{ 20 } \\
\hline & DMSO & $51.6 \pm 17.5 \%$ & $2.6 \%$ & $75.9 \pm 6.9 \%$ & $58.4 \pm 12.3 \%$ & \\
\hline & $t \mathrm{BuOH} / \mathrm{MeCN}^{\ddagger}$ & $20.1 \%$ & $0.3 \%$ & $18.3 \%$ & $13.4 \%$ & \\
\hline \multirow{3}{*}{$\mathrm{HPO}_{4}{ }^{2-}(2)$} & $\mathrm{MeCN}$ & $50 \pm 5.1 \%$ & $1.6 \pm 2.4 \%$ & $10.5 \pm 6.6 \%$ & $73.1 \pm 10.7 \%$ & \\
\hline & DMSO & $49.4 \pm 6.4 \%$ & $56.8 \pm 16.1 \%$ & $24.5 \pm 11.3 \%$ & $81.7 \pm 1.4 \%$ & \\
\hline & $t \mathrm{BuOH} / \mathrm{MeCN}^{\ddagger}$ & $13.7 \%$ & $8.9 \%$ & $14.7 \%$ & $8.1 \%$ & \\
\hline \multirow{3}{*}{$\mathrm{CO}_{3}{ }^{2-}(3)$} & $\mathrm{MeCN}$ & $53.8 \pm 12.6 \%$ & $33.5 \pm 11.6 \%$ & $85.3 \pm 1.3 \%$ & $75 \pm 2.2 \%$ & \\
\hline & DMSO & $75.4 \pm 8.3 \%$ & $55.9 \pm 16.3 \%$ & $85 \pm 2.6 \%$ & $58.1 \pm 8.1 \%$ & \\
\hline & $t \mathrm{BuOH} / \mathrm{MeCN}^{\ddagger}$ & $18.3 \%$ & $1.9 \%$ & $13.4 \%$ & $7.7 \%$ & \\
\hline \multirow{3}{*}{$\mathrm{PO}_{4}{ }^{3-}(4)$} & $\mathrm{MeCN}$ & $79.9 \pm 3.6 \%$ & $70.4 \pm 9.6 \%$ & $48.2 \pm 21 \%$ & $78.4 \pm 5.9 \%$ & \\
\hline & DMSO & $74.1 \pm 16.1 \%$ & $79.3 \pm 7 \%$ & $24.7 \pm 29.8 \%$ & $78.5 \pm 2.4 \%$ & \\
\hline & $t \mathrm{BuOH} / \mathrm{MeCN}^{\ddagger}$ & $18 \%$ & $17.7 \%$ & $4.7 \%$ & $13.3 \%$ & \\
\hline
\end{tabular}

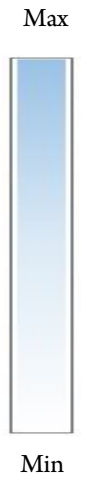

${ }^{*} \mathrm{n}=1$ due to low $(<10 \%)$ EE. $\ddagger \mathrm{n}=1$ due to low RCC. Complete table of data can be found in supporting information ( Table S10). 
Table 5. Tracers tested with the derived conditions from the model reaction. Reference procedures were reproduced manually and compared to derived conditions. Automated synthesis was performed and isolated RCY was compared to references. All results created within this work are based on $\mathrm{n}=3$. Synthetic schemes for precursors can be found in the supporting information Scheme S3-S5. Further details on the syntheses can be found in the SI Figure S20-49 and Table S11-20.

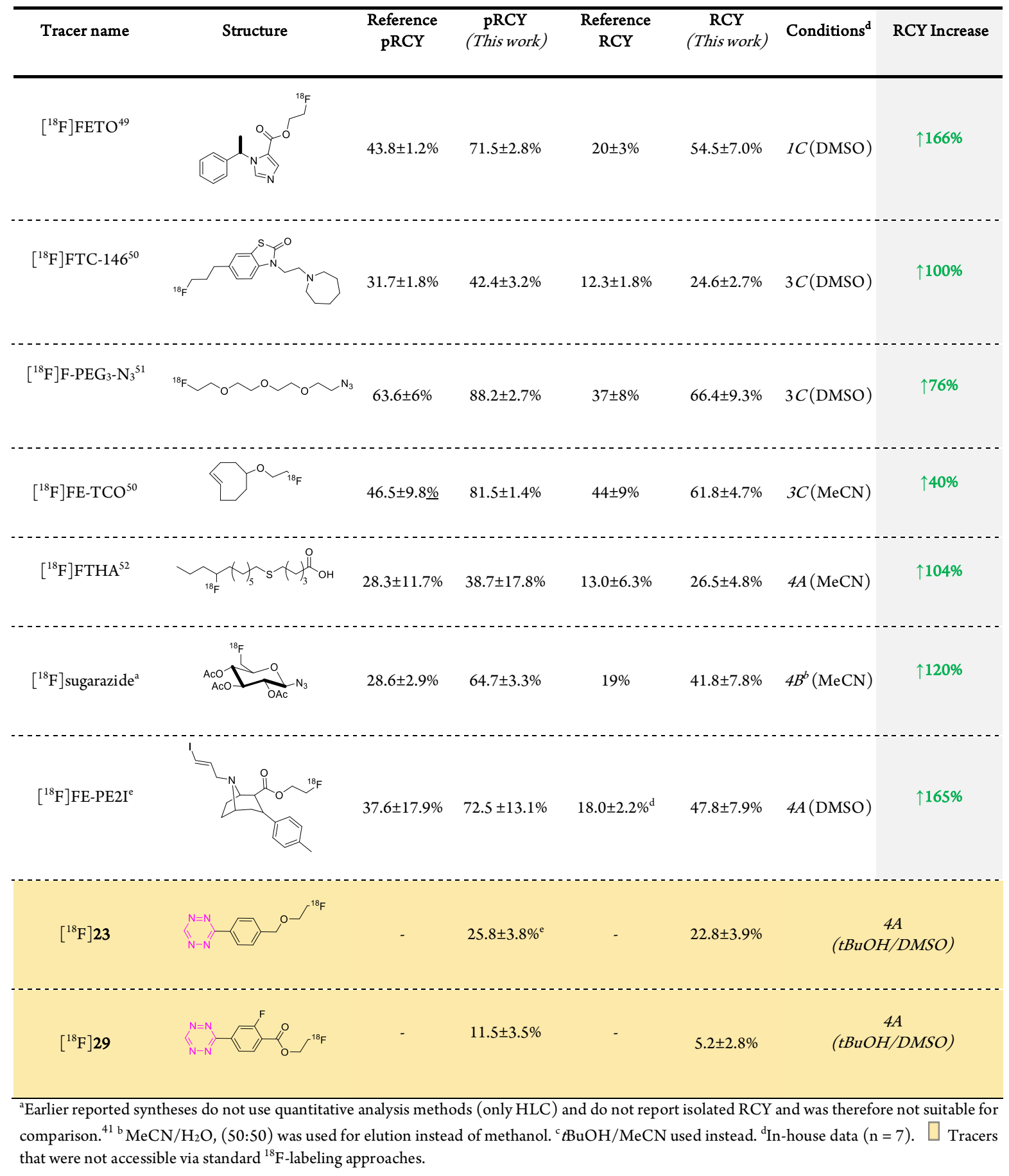

\section{Reaction time, temperature, precursor concentration and}

leaving groups. From literature it is known that the reaction time, temperature, precursor concentration as well as the chosen leaving group have a strong - but structure dependent - influence on RCYs. Therefore, we decided not to optimize these parameters for our model reaction and recommend that this should be investigated for individual syntheses.

Key findings. In order to minimize the base content during $S_{N} 2$ ${ }^{18}$ F-fluorinations while simultaneously maintaining good pRCYs, the following key parameters should be followed:
- Non-basic anions should be used for the elution process

- Multi-charged, non-nucleophilic preconditioning anions should be used

- Tetrabutylammonium counterions should be used for elution to increase resolubilization

- For very base sensitive compounds, $t \mathrm{BuOH}$ could be used in the reaction solvent to reduce degradation (with the expense of lowered reaction efficiency) 
Improving the labeling procedures of known radiopharmaceuticals/synthons. Next, we aimed to apply our findings (from Table 4) to the synthesis of a set of well-described PET tracers and radiolabeled building blocks and increase the RCYs of those structures thereby. We set out two criteria for compounds to be studied: I) Selected structures should possess a reported RCY $<50 \%$ and more importantly II) base-insensitive and base-sensitive structures should be included to study the beneficial effect of the identified conditions. We were also interested to cover a broad set of structural motifs which could be affected by a basic environment (Table 5). Preconditioning and elution conditions were selected on a rational analysis or by reported data of the base-sensitivity of compounds to be labeled and selected from Table 4.

First, four relatively base-insensitive tracers were tested. We hypothesized that even these structures could benefit from elution with tetraalkylammonium salts in respect to increasing the ${ }^{18} \mathrm{~F}$-resolubilization from the glass wall into the reaction solvent. $\left[{ }^{18} \mathrm{~F}\right] \mathrm{FETO}$, $\left[{ }^{18} \mathrm{~F}\right] \mathrm{FTC}-146,\left[{ }^{18} \mathrm{~F}\right] \mathrm{F}-\mathrm{PEG}_{3}-\mathrm{N}_{3}$ and $\left[{ }^{18} \mathrm{~F}\right] \mathrm{FE}-\mathrm{TCO}$ have been reported to be stable under "standard" basic labeling conditions. ${ }^{36-38,}$ No degradation adducts were observed using those conditions. We assumed that eluting a QMA which was preconditioned with $\mathrm{HCO}_{3}$ or the slightly more basic $\mathrm{CO}_{3}{ }^{2-}$ (conditions 1 Cor $3 C$, Table 4) with tetralkylammonium salts would result in higher ${ }^{18} \mathrm{~F}$ resolubilization while simultaneously the preconditioning anion would provide enough basicity to promote the labeling step. For all four compounds an increased isolated $\mathrm{RCY}$ was achieved spanning from approximately $40 \%$ to $170 \%$ increase using the optimized conditions (Table 5). Retrospective analysis of the ${ }^{18} \mathrm{~F}$-resolubilization data showed that this parameter was indeed in all reaction increased and significant contributed to the improvement RCY $(10-30 \%$ of the observed increase). One additional factor that might have improved the yields is the lower base content used. This condition rather favors $\mathrm{S}_{\mathrm{N}} 2$ labeling over E2 elimination - a possible side-reaction, which is typically facilitated at higher base concentrations.

The first relatively base-sensitive structure that was investigated in this study was $\left[{ }^{18} \mathrm{~F}\right]$ FTHA. This compound is labeled at a secondary carbon atom and thus, is more prone to undergo $\mathrm{E} 2$ elimination, especially under strongly basic conditions. ${ }^{39}$ We hypothesized that less basic conditions should consequently lead to a high RCY. Preconditioning with $\mathrm{PO}_{4}{ }^{3-}$ and using $\mathrm{Bu}_{4} \mathrm{OMs}$ for elution resulted in the lowest basicity of the eluent (conditions 4A, Table 4). Applying these conditions doubled the isolated RCY compared to the reference procedure using "standard" conditions (Table 5) ${ }^{40}$ The next compound tested was a building block which can be used to label a broad set of radiopharmaceuticals. ${ }^{41}\left[{ }^{18} \mathrm{~F}\right](2 \mathrm{R}, 3 \mathrm{R}, 4 \mathrm{~S}, 5 \mathrm{R}, 6 \mathrm{R})-2$-Azido-6(fluoromethyl)tetrahydro-2H-pyran-3,4,5-triyl triacetate $\left(\left[{ }^{18} \mathrm{~F}\right]\right.$ Sugarazide $)$ is labeled via a two-step labeling procedure. First, a hydroxy-group protected precursor is ${ }^{18} \mathrm{~F}$-labeled and then deprotected. The acetyl protection groups are base-labile. In the reported labeling procedure, partial hydrolysis of those protecting groups occurred using "standard" basic labeling conditions. Free hydroxy groups typically form $\mathrm{H}$-bonds with ${ }^{18} \mathrm{~F}$ and reduce its nucleophilicity, thus decreasing RCYs. We applied our low basicity conditions using a $\mathrm{PO}_{4}{ }^{3-}$ preconditioned QMA and $\mathrm{Bu}_{4} \operatorname{NOTf}(4 B)$ for elution in order to reduce the basicity and consequently reduce premature deprotection. No deprotection was observed using these conditions and the isolated RCY increased approximately two-fold to 41.8 $\pm 7.8 \%$ (Table 5, Supporting information Figure S33). ${ }^{55}$
Finally, we directed our focus towards $\left[{ }^{18} \mathrm{~F}\right] \mathrm{FE}-\mathrm{PE} 2 \mathrm{I}$. This tracer is regularly produced for clinical applications. The complex cocainescaffold along with a vinylic iodine has been shown to degrade in the reaction crude, presumably due to basic conditions. ${ }^{42}$ To investigate if lower basicity leads to higher RCYs, we used our low basicity conditions applying a $\mathrm{PO}_{4}{ }^{3-}$ preconditioned $\mathrm{QMA}$ and $\mathrm{Bu}_{4} \mathrm{NOMs}$ for elution ( $4 A$ ). The final isolated RCY was increased by over $150 \%$ using this set-up (Table 5).

Labeling of base-sensitive structures that are not accessible via "standard" aliphatic ${ }^{18} \mathrm{~F}$-labeling conditions. Tetrazines $(\mathrm{Tz})$ are a class of compounds which can be applied in pretargeted imaging. ${ }^{43-49}$ Currently, only low reactivity Tzs can be radiolabeled via direct aliphatic $S_{\mathrm{N}} 2 .{ }^{50}$ Unfortunately, these structures display too low reactivity for in vivo bioorthogonal chemistry approaches. ${ }^{51}$ Highly reactive structures such as mono-unsubstituted tetrazines ( $\mathrm{H}-\mathrm{Tzs})$ have been reported to be highly sensitive to base. ${ }^{52}$ Extensive degradation is observed which prevents isolation of meaningful amounts for imaging studies. Using "standard" conditions, no or only trace amounts of the radiolabeled product could be observed (Supporting information Figure SSO and Li et al. ${ }^{52}$ ). We hypothesized that our mildest labeling conditions $(4 A)$ in combination with a $t \mathrm{BuOH}$-mixture could provide sufficiently low basicity labeling conditions to label a H-Tz. Initial attempts using a mesylate precursor resulted in an increase from traces of labeled product to a $\mathrm{pRCY}$ of approximately $2 \%$ of $\left[{ }^{18} \mathrm{~F}\right] \mathbf{2 3}$. In a next step, we investigated the influence of different leaving groups. In addition to the mesylate $(\mathrm{OMs})$ group, we tested tosylate (OTs) - and nosylate (ONs)based precursors. As mentioned previously, different leaving groups can influence the labeling yield substantially, but no trend with respect to increased RCY has been observed, and the yields varied by case-by-case scenario depending on the individual molecular structure of the precursor. ${ }^{53}$ To facilitate the reaction, further the solvent was changed to $t \mathrm{BuOH}$ mixed with DMSO which decreased the evaporation of solvent during automated synthesis while maintaining the RCC (Supporting information Table S2O). The nosylate precursor with $t \mathrm{BuOH} / \mathrm{DMSO}$ and the low basicity elution condition (4A) resulted in a RCY of approximately $22 \%$ (Figure 4). Control experiments were also carried out to investigate if low basicity conditions ( $4 A$ in combination with a $\mathrm{BuOH}$ solvent) are needed to promote the reaction.

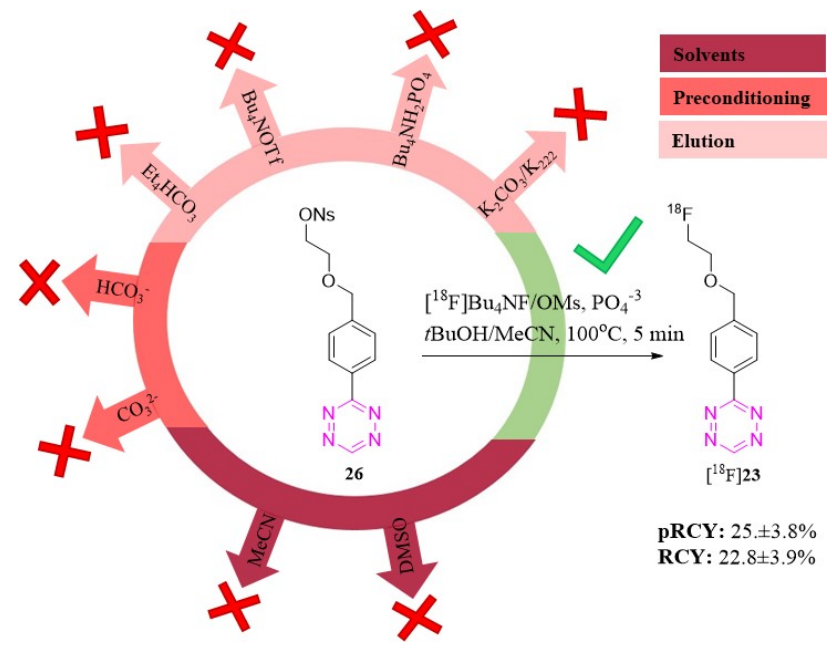

Figure 4. ${ }^{18} \mathrm{~F}$-Labeling of a base-sensitive structures that is not accessible using "standard" aliphatic labeling conditions. The H-Tz $\left(\left[{ }^{18} \mathrm{~F}\right] 23\right)$ could only be labeled using low basicity conditions identified within this work, i.e. $4 A$ in combination with $t \mathrm{BuOH} / \mathrm{MeCN}$. 
These experiments yielded in no or only trace amount of the ${ }^{18} \mathrm{~F}$-labeled $\mathrm{Tz}\left(\left[{ }^{18} \mathrm{~F}\right] 23\right)$. In order to test the applicability of the identified conditions to label H-Tzs, we decided to radiolabel an even more reactive $\mathrm{Tz}$. The chosen structure displays a 4-fold increased reactivity towards TCO $\left(2676 \mathrm{M}^{-1} \mathrm{~s}^{-1}\right.$ vs. $682 \mathrm{M}^{-1} \mathrm{~s}^{-1}$ Supporting information Table $S 21)^{50}$ and should as such be even more difficult to label, since reactivity is proportional to the Tz's base stability (Table 5 and Supporting information Table S2O). In line with the aforementioned observations, the more reactive $\mathrm{Tz}\left(\left[{ }^{18} \mathrm{~F}\right] 29\right)$ could only be radiolabeled using the mildest labeling conditions. As expected, the compound could be isolated from the ONs precursor in a lower RCY (ca. $5 \% \mathrm{RCY}$ ) than the less reactive $\mathrm{Tz}$. This reflects the higher base sensitivity of the structure.

Recommendations for aliphatic ${ }^{18} \mathrm{~F}$-radiolabeling attempts. Our results indicate that the following labeling conditions should be used as a starting point to label aliphatic structures:

- Base-sensitive tracers/precursors: $t \mathrm{BuOH}$-mixtures or similar hindered protic solvents should be used in combination with condition $4 A$ or $4 B$.

- Moderately base-sensitive compounds: conditions $4 A$ or $4 B$ in combination with $\mathrm{MeCN}$ or DMSO should be used.

- Base-insensitive structures: $1 C$ or $3 C$ in $\mathrm{DMSO}$ are robust high yielding conditions, alternatively conventional methods using tetraalkylated carbonates should be used.

A

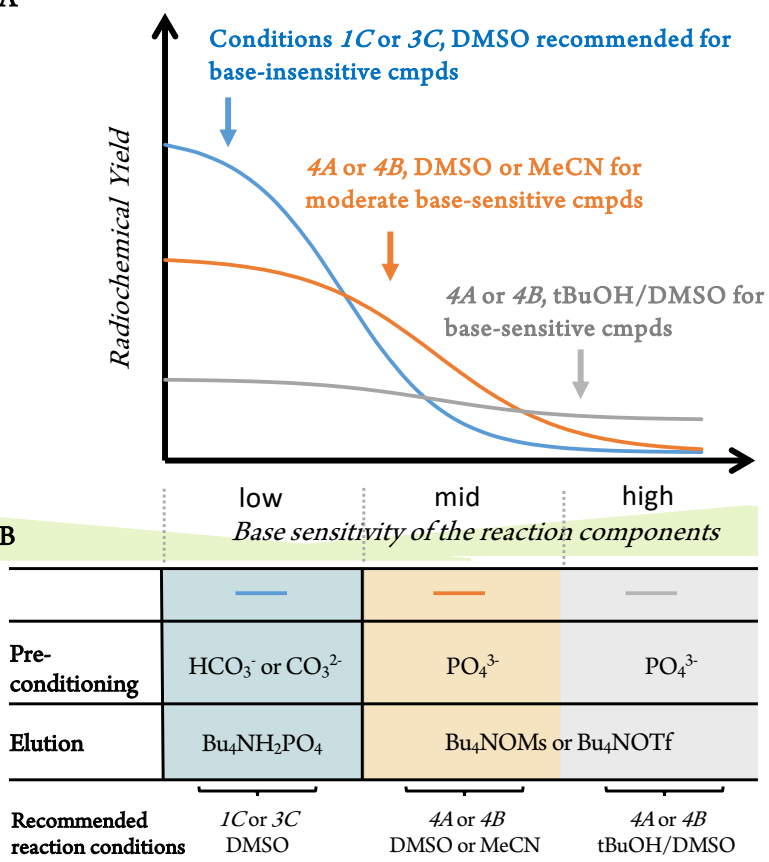

Figure 5. Recommendations for ${ }^{18} \mathrm{~F}$-labeling of aliphatic substrates. Conditions represent parameters that we suggest to apply as a starting point before further optimization with respect to reaction time, temperature, precursor concentration and leaving groups. Detailed reaction conditions can be found in Table 4 and the Supporting Information Table S2O.

\section{Conclusions}

By carefully studying the key parameters involved in the trapping of $\left[{ }^{18} \mathrm{~F}\right]$ fluoride on an anion exchange cartridge and its subsequent elution, we were able to identify conditions that result in low basicity elutions. These conditions enable us to radiolabel base sensitive structures with significantly improved RCYs. Even structures that were previously not accessible by applying "standard" aliphatic ${ }^{18} \mathrm{~F}$ labeling strategies could be radiolabeled. The developed methodology can easily be implemented on all synthesis modules and is only dependent on the preconditioning of the anion exchange cartridge, its non-basic elution and on the selection of the right reaction solvent. This places new classes of ${ }^{18} \mathrm{~F}$-fluorinated compounds within the reach of classical labeling approaches $\left(S_{N} 2\right.$ labeling).

\section{ASSOCIATED CONTENT}

\section{Supporting Information}

The Supporting Information (SI) is available free of charge on the ACS Publications website. Detailed experimental procedures, characterization of novel structures and labeling protocols are provided.

\section{AUTHOR INFORMATION}

\section{Corresponding Author}

* Matthias M. Herth - University of Copenhagen, Copenhagen, Denmark, Email: matthias.herth@sund.ku.dk

\section{Author Contributions}

The elution screening experiments were conducted by KB, VS and INP. Precursor synthesis was done by KB, UB and SLB and subsequent radiolabeling experiments was performed by KB. The study was conceptionally designed and the manuscript written by $\mathrm{KB}$, VS and $\mathrm{MHH}$ with contribution from all authors. All authors have given approval to the final version of the manuscript.

\section{Funding Sources}

This project has received funding from European Union's Horizon 2020 research and innovation program under the Marie Skłodowska-Curie Grant Agreement No. 813528. MMH have received funding from the European Union's EU Framework Program for Research and Innovation Horizon 2020 (grant agreement no. 670261). VS was supported by BRIDGE - Translational Excellence Program at the Faculty of Health and Medical Sciences, University of Copenhagen, funded by the Novo Nordisk Foundation (grant agreement no. NNF18SA0034956). The Lundbeck Foundation, the Innovation Fund Denmark, and the Research Council for Independent Research are further acknowledged.

\section{Notes}

The authors declare no conflicts of interest.

\section{ACKNOWLEDGMENT}

We thank the staff at the Department of Radiation Physics (Skåne University Hospital) and the Department of Clinical Physiology, Nuclear Medicine \& PET, Rigshospitalet, for the production of fluorine-18, technical assistance and support.

\section{REFERENCES}

Piel, M.; Vernaleken, I.; Rösch, F. Positron Emission Tomography in CNS Drug Discovery and Drug Monitoring. J. Med. Chem. 2014, 57 (22), 9232-9258. https://doi.org/10.1021/jm5001858.

Ametamey, S. M.; Honer, M.; Schubiger, P. A. Molecular Imaging with PET. Chem. Rev. 2008, 108 (5), 1501-1516. https://doi.org/10.1021/cr0782426.

Varlow, C.; Szames, D.; Dahl, K.; Bernard-Gauthier, V.; Vasdev, N. Fluorine-18: An Untapped Resource in Inorganic Chemistry. Chem. Commun. 2018, 54 (84), 11835-11842. https://doi.org/10.1039/c8cc04751k. 
Discovery. In Textbook of Drug Design and Discovery; Strømgaard, K., Krogsgaard-Larsen, P., Madsen, U., Eds.; CRC Press: Copenhagen, 2017.

(5)

Edem, P. E.; Steen, E. J. L.; Kjær, A.; Herth, M. M. Fluorine-18 Radiolabeling Strategies-Advantages and Disadvantages of Currently Applied Labeling Methods. In Late-Stage Fluorination of Bioactive Molecules and Biologically-Relevant Substrates; Elsevier Inc.: Buenos Aires, 2019; pp 29-103. https://doi.org/10.1016/b978-0-12-812958-6.00002-1.

(6)

Beejot, R.; Gouverneur, V. Fluorine In Pharmaceutical And Medicinal Chemistry: From Biophysical Aspects To Clinical Applications, Volume 6.; Gouverneur, V., Muller, K., Eds.; World Scientific, 2012.

(7) Deng, X.; Rong, J.; Wang, L.; Vasdev, N.; Zhang, L.; Josephson, L.; Liang, S. H. Chemistry for Positron Emission Tomography: Recent Advances in ${ }^{11} \mathrm{C}$-, ${ }^{18} \mathrm{~F}-,{ }^{13} \mathrm{~N}$-, and ${ }^{15} \mathrm{O}$ Labeling Reactions. Angew. Chemie - Int. Ed. 2019, 58 (9), 2580-2605. https://doi.org/10.1002/anie.201805501.

(8) Mossine, A. V.; Brooks, A. F.; Ichiishi, N.; Makaravage, K. J.; Sanford, M. S.; Scott, P. J. H. Development of Customized $\left[{ }^{18} \mathrm{~F}\right]$ Fluoride Elution Techniques for the Enhancement of Copper-Mediated Late-Stage Radiofluorination. Sci. Rep. 2017, 7 (1), 1-9. https://doi.org/10.1038/s41598-01700110-1.

(9) He, P.; Haswell, S. J.; Pamme, N.; Archibald, S. J. Advances in Processes for PET Radiotracer Synthesis: Separation of $\left[{ }^{18} \mathrm{~F}\right]$ Fluoride from Enriched $\left[{ }^{18} \mathrm{O}\right]$ Water. Appl. Radiat. Isot. 2014, 91, 64-70. https://doi.org/10.1016/j.apradiso.2014.04.021.

(10) Katsifis, A.; Hamacher, K.; Schnitter, J.; Stöcklin, G. Optimization Studies Concerning the Direct Nucleophilic Fluorination of Butyrophenone Neuroleptics. Appl. Radiat. Isot. $1993, \quad 44 \quad$ (7), 1015-1020. https://doi.org/10.1016/0969-8043(93)90005-U.

(11) Pees, A.; Windhorst, A. D.; Vosjan, M. J. W. D.; Tadino, V.; Vugts, D. J. Synthesis of $\left[{ }^{18} \mathrm{~F}\right]$ Fluoroform with High Molar Activity. European J. Org. Chem. 2020, 2020(9), 1177-1185. https://doi.org/10.1002/ejoc.202000056.

(12) Seo, J. W.; Lee, B. S.; Lee, S. J.; Oh, S. J.; Chi, D. Y. Fast and Easy Drying Method for the Preparation of Activated [ ${ }^{18}$ F]Fluoride Using Polymer Cartridge. Bull. Korean Chem. Soc. 2011, 32 (1), 71-76. https://doi.org/10.5012/bkcs.2011.32.1.71.

(13) Iwata, R.; Pascali, C.; Terasaki, K.; Ishikawa, Y.; Furumoto, S.; Yanai, K. Minimization of the Amount of Kryptofix 222 $\mathrm{KHCO}_{3}$ for Applications to Microscale ${ }^{18} \mathrm{~F}$-Radiolabeling. Appl. Radiat. Isot. 2017, 125 (April), 113-118. https://doi.org/10.1016/j.apradiso.2017.04.021.

(14) Lemaire, C. F.; Aerts, J.J.; Voccia, S.; Libert, L. C.; Mercier, F.; Goblet, D.; Plenevaux, A. R; Luxen, A. J. Fast Production of Highly Reactive No-Carrier-Added $\left[{ }^{18} \mathrm{~F}\right]$ Fluoride for the Labeling of Radiopharmaceuticals. Angew. Chemie - Int. Ed. 2010, 49 (18), 3161-3164. https://doi.org/10.1002/anie.200906341.

(15) Maisonial-Besset, A.; Serre, A.; Ouadi, A.; Schmitt, S.; Canitrot, D.; Léal, F.; Miot-Noirault, E.; Brasse, D.; Marchand, P.; Chezal, J. M. Base/Cryptand/Metal-Free Automated Nucleophilic Radiofluorination of $\left[{ }^{18} \mathrm{~F}\right] \mathrm{FDOPA}$ from Iodonium Salts: Importance of Hydrogen Carbonate Counterion. European J. Org. Chem. 2018, 2018 (48), 70587065. https://doi.org/10.1002/ejoc.201801608.
(16) Richarz, R.; Krapf, P.; Zarrad, F.; Urusova, E. A.; Neumaier, B.; Zlatopolskiy, B. D. Neither Azeotropic Drying, nor Base nor Other Additives: A Minimalist Approach to ${ }^{18} \mathrm{~F}$-Labeling. Org. Biomol. Chem. 2014, 12 (40), 8094-8099. https://doi.org/10.1039/C4OB01336K.

(17) Pees, A.; Sewing, C.; Vosjan, M. J. W. D.; Tadino, V.; Herscheid, J. D. M.; Windhorst, A. D.; Vugts, D. J. Fast and Reliable Generation of $\left[{ }^{18} \mathrm{~F}\right]$ Triflyl Fluoride, a Gaseous $\left[{ }^{18} \mathrm{~F}\right]$ Fluoride Source. Chem. Commun. 2018, 54 (72), 10179-10182. https://doi.org/10.1039/c8cc03206h.

(18) Petersen, I. N.; Kristensen, J. L.; Herth, M. M. Nucleophilic ${ }^{18} \mathrm{~F}$-Labeling of Spirocyclic Iodonium Ylide or Boronic Pinacol Ester Precursors: Advantages and Disadvantages. European J. Org. Chem. 2017, 2017 (3), 453-458. https://doi.org/10.1002/ejoc.201601448.

(19) van der Born, D.; Pees, A.; Poot, A. J.; Orru, R. V. A.; Windhorst, A. D.; Vugts, D. J. Fluorine-18 Labelled Building Blocks for PET Tracer Synthesis. Chem. Soc. Rev. 2017, 46 (15), 4709-4773. https://doi.org/10.1039/C6CS00492J.

(20) Taylor, N. J.; Emer, E.; Preshlock, S.; Schedler, M.; Tredwell, M.; Verhoog, S.; Mercier, J.; Genicot, C.; Gouverneur, V. Derisking the Cu-Mediated ${ }^{18} \mathrm{~F}$-Fluorination of Heterocyclic Positron Emission Tomography Radioligands. J. Am. Chem. Soc. 2017, 139 (24), 8267-8276. https://doi.org/10.1021/jacs.7b03131.

(21) Graham, T. J. A.; Lambert, R. F.; Ploessl, K.; Kung, H. F.; Doyle, A. G. Enantioselective Radiosynthesis of Positron Emission Tomography (PET) Tracers Containing $\left[{ }^{18} \mathrm{~F}\right]$ Fluorohydrins. J. Am. Chem. Soc. 2014, 136(14), 52915294. https://doi.org/10.1021/ja5025645.

(22) Coenen, H. H.; Gee, A. D.; Adam, M.; Antoni, G.; Cutler, C. S.; Fujibayashi, Y.; Jeong, J. M.; Mach, R. H.; Mindt, T. L.; Pike, V. W.; et al. Consensus Nomenclature Rules for Radiopharmaceutical Chemistry - Setting the Record Straight. Nucl. Med. Biol. 2017, 55, v-xi. https://doi.org/10.1016/j.nucmedbio.2017.09.004.

(23) Zhang, X.; Basuli, F.; Swenson, R. E. An Azeotropic DryingFree Approach for Copper-Mediated Radiofluorination without Addition of Base. J. Label. Compd. Radiopharm. 2019, 62 (3), 139-145. https://doi.org/10.1002/jlcr.3705.

(24) Herth, M. M.; Ametamey, S.; Antuganov, D.; Bauman, A.; Berndt, M.; Brooks, A. F.; Bormans, G.; Seong, Y.; Gillings, N.; Häfeli, U. O.; et al. On the Consensus Nomenclature Rules for Radiopharmaceutical Chemistry - Reconsideration of Radiochemical Conversion. Nucl. Med. Biol. 2021, 93, 19-21. https://doi.org/10.1016/j.nucmedbio.2020.11.003.

(25) Roeda, D.; Dolle, F. Aliphatic Nucleophilic Radiofluorination. Curr. Radiopharm. 2010, 3 (2), 81-108. https://doi.org/10.2174/1874471011003020081.

(26) Antuganov, D.; Zykov, M.; Timofeev, V.; Timofeeva, K.; Antuganova, Y.; Orlovskaya, V.; Fedorova, O.; Krasikova, R. Copper-Mediated Radiofluorination of Aryl Pinacolboronate Esters: A Straightforward Protocol by Using Pyridinium Sulfonates. European J. Org. Chem. 2019, 2019(5), 918-922. https://doi.org/10.1002/ejoc.201801514.

(27) Mossine, A. V.; Brooks, A. F.; Makaravage, K. J.; Miller, J. M.; Ichiishi, N.; Sanford, M. S.; Scott, P. J. H. Synthesis of $\left[{ }^{18} \mathrm{~F}\right]$ Arenes via the Copper-Mediated $\left[{ }^{18} \mathrm{~F}\right]$ Fluorination of Boronic Acids. Org. Lett. 2015, 17 (23), 5780-5783. https://doi.org/10.1021/acs.orglett.5b02875.

(28) Zlatopolskiy, B. D.; Zischler, J.; Krapf, P.; Zarrad, F.; Urusova, 
E. A.; Kordys, E.; Endepols, H.; Neumaier, B. CopperMediated Aromatic Radiofluorination Revisited: Efficient Production of PET Tracers on a Preparative Scale. Chem. - $A$ Eur. J. 2015, 21 (15), 5972-5979. https://doi.org/10.1002/chem.201405586.

(29) Khamwan, K.; Krisanachinda, A.; Pasawang, P. The Determination of Patient Dose from ${ }^{18} \mathrm{~F}-\mathrm{FDG}$ PET/CT Examination. Radiat. Prot. Dosimetry 2010, 141 (1), 50-55. https://doi.org/10.1093/rpd/ncq140.

(30) Lee, S. J.; Oh, S. J.; Chi, D. Y.; Moon, D. H.; Ryu, J. S. High Yielding $\left[{ }^{18} \mathrm{~F}\right]$ Fluorination Method by Fine Control of the Base. Bull. Korean Chem. Soc. 2012, 33 (7), 2177-2180. https://doi.org/10.5012/bkcs.2012.33.7.2177.

(31) Harland, C. E. Ion Exchange: Theory and Practice, 2nd editio.; ISSN; Royal Society of Chemistry: Cambridge, 1994.

(32) Reijenga, J.; van Hoof, A.; van Loon, A.; Teunissen, B. Development of Methods for the Determination of PKa Values. Anal. Chem. Insights 2013, 8 (1), 53-71. https://doi.org/10.4137/ACI.S12304.

(33) Kütt, A.; Selberg, S.; Kaljurand, I.; Tshepelevitsh, S.; Heering, A.; Darnell, A.; Kaupmees, K.; Piirsalu, M.; Leito, I. PKa Values in Organic Chemistry - Making Maximum Use of the Available Data. Tetrahedron Lett. 2018, 59(42), 3738-3748. https://doi.org/10.1016/j.tetlet.2018.08.054.

(34) Reed, C. D.; Launay, G. G.; Carroll, M. A. Evaluation of Tetraethylammonium Bicarbonate as a Phase-Transfer Agent in the Formation of $\left[{ }^{18} \mathrm{~F}\right]$ Fluoroarenes. J. Fluor. Chem. 2012, 143 , 231-237. https://doi.org/10.1016/j.jfluchem.2012.07.015.

(35) Brichard, L.; Aigbirhio, F. I. An Efficient Method for Enhancing the Reactivity and Flexibility of $\left[{ }^{18} \mathrm{~F}\right]$ Fluoride towards Nucleophilic Substitution Using Tetraethylammonium Bicarbonate. European J. Org. Chem. 2014, $2014 \quad$ (28), 6145-6149. https://doi.org/10.1002/ejoc.201402587.

(36) Rahman, O.; Erlandsson, M.; Blom, E.; Långström, B. Automated Synthesis Of ${ }^{18} \mathrm{~F}$-Labelled Analogs of Metomidate, Vorozole and Harmine Using Commercial Platform. J. Label. Compd. Radiopharm. 2010, 53 (4), 169-171. https://doi.org/10.1002/jlcr.1742.

Collins, J.; Waldmann, C. M.; Drake, C.; Slavik, R.; Ha, N. S.; Sergeev, M.; Lazari, M.; Shen, B.; Chin, F. T.; Moore, M.; et al. Production of Diverse PET Probes with Limited Resources: $24{ }^{18}$ F-Labeled Compounds Prepared with a Single Radiosynthesizer. Proc. Natl. Acad. Sci. U. S. A. 2017, 114 (43),

11309-11314. https://doi.org/10.1073/pnas.1710466114.

(38) Shen, B.; Jeon, J.; Palner, M.; Ye, D.; Shuhendler, A.; Chin, F. T.; Rao, J. Positron Emission Tomography Imaging of DrugInduced Tumor Apoptosis with a Caspase-Triggered Nanoaggregation Probe. Angew. Chemie - Int. Ed. 2013, 52 (40), 10511-10514. https://doi.org/10.1002/anie.201303422.

(39) Pliego, J. R.; Piló-Veloso, D. Chemoselective Nucleophilic Fluorination Induced by Selective Solvation of the $\mathrm{S}_{\mathrm{N}} 2$ Transition State. J. Phys. Chem. B2007, 111 (7), 1752-1758. https://doi.org/10.1021/jp066580p.

(40) Savisto, N.; Viljanen, T.; Kokkomäki, E.; Bergman, J.; Solin, O. Automated Production of $\left[{ }^{18} \mathrm{~F}\right] \mathrm{FTHA}$ According to GMP. $J$. Label. Compd. Radiopharm. 2018, 61 (2), 84-93. https://doi.org/10.1002/jlcr.3589.
(41) Maschauer, S.; Haubner, R.; Kuwert, T.; Prante, O. ${ }^{18}$ F-GlycoRGD Peptides for PET Imaging of Integrin Expression: Efficient Radiosynthesis by Click Chemistry and Modulation of Biodistribution by Glycosylation. Mol. Pharm. 2014, 11 (2), 505-515. https://doi.org/10.1021/mp4004817.

Stepanov, V.; Krasikova, R.; Raus, L.; Loog, O.; Hiltunen, J.; Halldin, C. An Efficient One-Step Radiosynthesis of $\left[{ }^{18} \mathrm{~F}\right] \mathrm{FE}-$ PE2I, a PET Radioligand for Imaging of Dopamine Transporters. J. Label. Compd. Radiopharm. 2012, 55 (6), 206-210. https://doi.org/10.1002/jlcr.2927.

(43) Stéen, E. J. L.; Edem, P. E.; Nørregaard, K.; Jørgensen, J. T.; Shalgunov, V.; Kjaer, A.; Herth, M. M. Pretargeting in Nuclear Imaging and Radionuclide Therapy: Improving Efficacy of Theranostics and Nanomedicines; 2018; Vol. 179. https://doi.org/10.1016/j.biomaterials.2018.06.021.

(44) Rossin, R.; Verkerk, P. R.; Van Den Bosch, S. M.; Vulders, R. C. M.; Verel, I.; Lub, J.; Robillard, M. S. In Vivo Chemistry for Pretargeted Tumor Imaging in Live Mice. Angew. Chemie Int. Ed. 2010, 49 (19), 3375-3378. https://doi.org/10.1002/anie.200906294.

(45) Meyer, J. P.; Houghton, J. L.; Kozlowski, P.; Abdel-Atti, D.; Reiner, T.; Pillarsetty, N. V. K.; Scholz, W. W.; Zeglis, B. M.; Lewis, J. S. ${ }^{18}$ F-Based Pretargeted PET Imaging Based on Bioorthogonal Diels-Alder Click Chemistry. Bioconjug. Chem. 2016, 27 (2), 298-301. https://doi.org/10.1021/acs.bioconjchem.5b00504.

(46) Hou, S.; Choi, J. S.; Garcia, M. A.; Xing, Y.; Chen, K. J.; Chen, Y. M.; Jiang, Z. K.; Ro, T.; Wu, L.; Stout, D. B.; et al. Pretargeted Positron Emission Tomography Imaging That Employs Supramolecular Nanoparticles with in Vivo Bioorthogonal Chemistry. ACS Nano 2016, 10 (1), 14171424. https://doi.org/10.1021/acsnano.5b06860.

(47) Edem, P. E.; Jørgensen, J. T.; Nørregaard, K.; Rossin, R; Yazdani, A.; Valliant, J. F.; Robillard, M.; Herth, M. M.; Kjaer, A. Evaluation of a ${ }^{68} \mathrm{Ga}$-Labeled DOTA-Tetrazine as a PET Alternative to $111 \mathrm{In}$-SPECT Pretargeted Imaging. Molecules 2020, $25 \quad$ (3), 1-14 https://doi.org/10.3390/molecules25030463.

(48) Herth, M. M.; Andersen, V.L.; Lehel, S.; Madsen, J.; Knudsen, G. M.; Kristensen, J. L. Development of a ${ }^{11} \mathrm{C}$-Labeled Tetrazine for Rapid Tetrazine-Trans-Cyclooctene Ligation. Chem. Commun. 2013, 49 (36), 3805-3807. https://doi.org/10.1039/c3cc41027g.

(49) Denk, C.; Svatunek, D.; Mairinger, S.; Stanek, J.; Filip, T.; Matscheko, D.; Kuntner, C.; Wanek, T.; Mikula, H. Design, Synthesis, and Evaluation of a Low-Molecular-Weight ${ }^{11} \mathrm{C}$ Labeled Tetrazine for Pretargeted PET Imaging Applying Bioorthogonal in Vivo Click Chemistry. Bioconjug. Chem. 2016, $27 \quad$ (7), 1707-1712. https://doi.org/10.1021/acs.bioconjchem.6b00234.

(50) Denk, C.; Svatunek, D.; Filip, T.; Wanek, T.; Lumpi, D.; Fröhlich, J.; Kuntner, C.; Mikula, H. Development of a ${ }^{18} \mathrm{~F}$ Labeled Tetrazine with Favorable Pharmacokinetics for Bioorthogonal PET Imaging. Angew. Chemie - Int. Ed. 2014, 53 (36), 9655-9659. https://doi.org/10.1002/anie.201404277.

(51) Rossin, R.; Robillard, M. S. Pretargeted Imaging Using Bioorthogonal Chemistry in Mice. Curr. Opin. Chem. Biol. 2014, 21, 161-169. https://doi.org/10.1016/j.cbpa.2014.07.023.

(52) Li, Z.; Cai, H.; Hassink, M.; Blackman, M. L.; Brown, R. C. D.; 
Conti, P. S.; Fox, J. M. Tetrazine-Trans-Cyclooctene Ligation for the Rapid Construction of ${ }^{18} \mathrm{~F}$-Labeled Probes. Chem. Commun. 2010, 46 (42), 8043-8045. https://doi.org/10.1039/c0cc03078c.

(53) Rötering, S.; Scheunemann, M.; Günther, R.; Löser, R.; Hiller, A.; Dan Peters; Brust, P.; Fischer, S.; Steinbach, J. Tos-NosMos: Synthesis of Different Aryl Sulfonate Precursors for the Radiosynthesis of the Alpha7 Nicotinic Acetylcholine Receptor Radioligand $\left[{ }^{18} \mathrm{~F}\right] \mathrm{NS} 14490$. Appl. Radiat. Isot. 2016, 114, 57-62. https://doi.org/10.1016/j.apradiso.2016.04.028.

(54) Ripin, D. H.; Evans, D. A. Aqueous pKa compilation with some dimethyl sulfoxide values http://ccc.chem.pitt.edu/wipf/MechOMs/evans_pKa_table .pdf (accessed Dec 11, 2020).

(55) Stéen, E. J. L.; Jørgensen, J. Y.; , Denk, C.; Battisti, U.M.; Nørregaard, K.; Edem, P.; Bratteby, K.; Shalgunov, V.; Wilkovitsch, M.; Svatunek, D.; Poulie, C. B. M.; Hvass, L.; Simón, M.; Wanek, T.; Rossin, R.; Robillard, M.; Kristensen,
J.L.; Mikula, H.; Kjaer, A.; Herth, M.M. Lipophilicity and Click Reactivity Determine the Performance of Bioorthogonal Tetrazine Tools in Pretargeted In Vivo Chemistry. ACS Pharmacol. Transl. Sci. https://dx.doi.org/10.1021/acsptsci.1c00007 


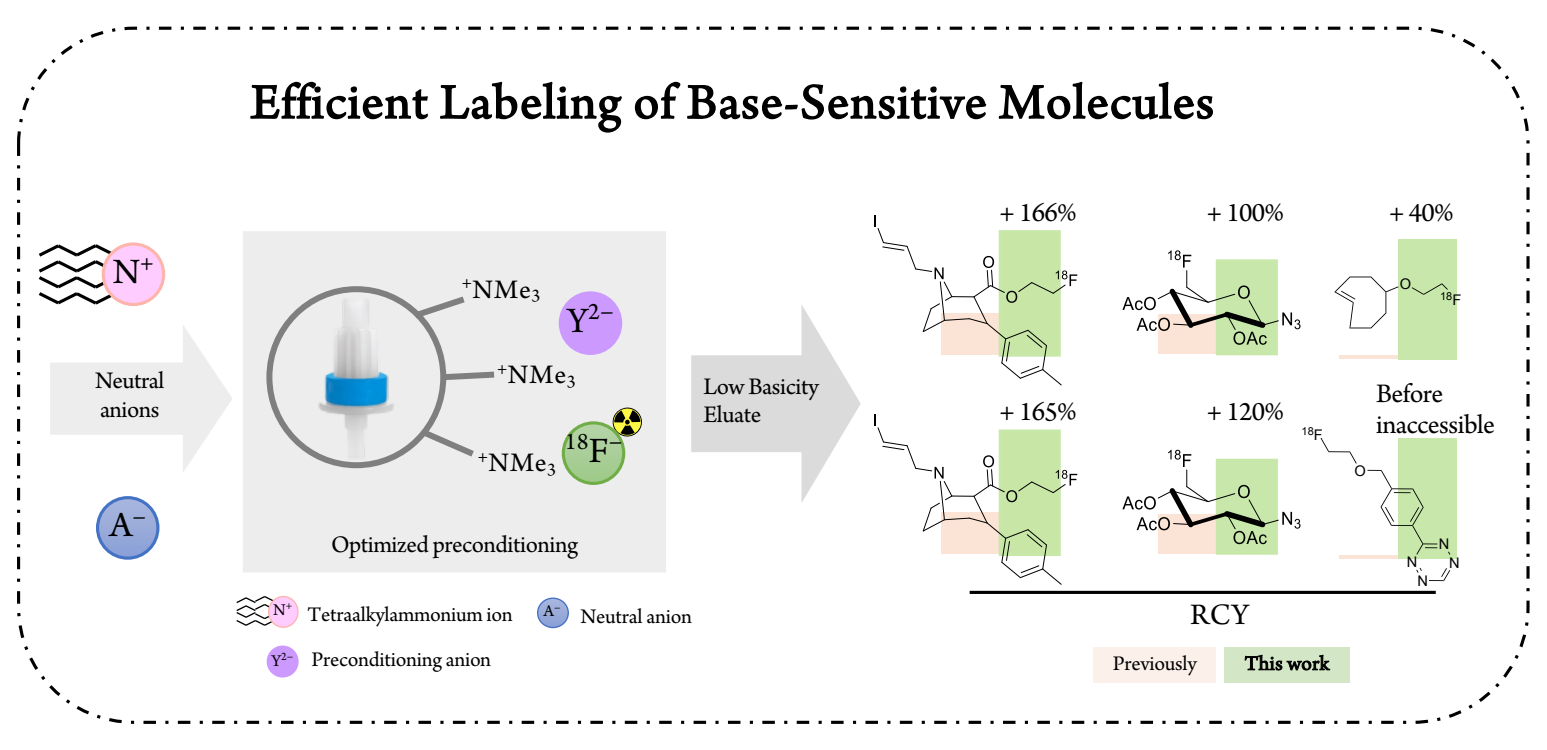

